\title{
Aproximação do setor público do setor privado visando o fortalecimento do SUS
}

\author{
Convegence of public and private sectors to strengthening the SUS
}

\section{Elisabete Lira Quelhas Montaño}

Advogada, Especialista em Direito da Medicina. Secretaria Municipal de Saúde de São Bernardo do Campo, Brasil.

\section{Francisco Torres Troccoli}

Médico. Diretor da Divisão de Regulação da Secretaria Municipal de São Bernardo do Campo, Brasil.

\section{Caroline Regina Teixeira de Freitas}

Advogada. Coordenadora técnica da Secretaria Municipal de Saúde, Brasil.

Resumo: Conhecer a saúde suplementar no âmbito do município é conhecer a totalidade do SUS. O município de São Bernardo do Campo tem uma cobertura de saúde suplementar superior a $60 \%$ da população, mas pouco se conhece dessa população. Entendendo a necessidade de articulação do SUS com a saúde suplementar e visando a corresponsabilização das ações de saúde no município, criou-se a gerência de regulação em saúde suplementar, marcada pela transversalidade em suas articulações. Desde sua criação, várias articulações tem sido feitas com ouvidoria, serviço social, vigilância sanitária, setor de informação, controle e avaliação, auditoria, tendo como principal objetivo a melhoria da qualidade e a sistematização de informações a respeito da saúde suplementar, conhecer a carga instalada nos serviços, bem como seu desempenho. Colocou-se aos atores do setor privado a impossibilidade de planejar a saúde do município sem essa articulação. Conseguimos um cadastro municipal mais próximo da realidade dos serviços. Foi realizado o $1^{\circ}$ Encontro Regional de Saúde Suplementar, do qual resultou a primeira pactuação entre as esferas pública e privada no sentido de uma construção conjunta fortalecendo o SUS local. Outra ação importante foi à aproximação com o setor privado visando à redução da mortalidade materno-infantil, sendo que uma parcela significativa desses óbitos era da saúde suplementar e, sem uma ação conjunta, não conseguiríamos a redução da mortalidade. Outra ação muito importante foi o olhar de regulação estatal sobre o setor privado.

Palavras chave: Setor Público, Setor Privado.

Key-words: Private Health Sector, Public Health Sector 
O Sistema Único de Saúde é estudado por nós a todo tempo. Estudamos seus princípios, epidemiologia, financiamento, e são tantas as vertentes, sobre as quais muitas delas ainda não temos consenso. Sempre buscamos o melhor; quer seja o perfil epidemiológico de uma população onde buscamos melhorar as taxas de mortalidade, quer o perfil demográfico buscando a diminuição de vulnerabilidades.

Mas uma coisa é certa, sempre olhamos a população como um todo; como premissa partimos sempre do todo, para depois refinar qualquer estudo. Quando o assunto é planejamento aí nem se fala, o estudo demográfico número de habitantes de uma determinada área é imprescindível.

O município de São Bernardo do Campo, através da Secretaria Municipal de Saúde, buscando o fortalecimento do SUS no âmbito municipal, entendia a necessidade de conhecer a população que não é 100\% SUS dependente, ou seja, munícipes que possuíam planos de saúde privados. Sabendo das atribuições legais da Agência Nacional de Saúde Suplementar, mas sabendo também que a função de regulação estatal existe dentro do município, surgem duas perguntas: até aonde ir? 0 que fazer? Para nós, a dificuldade imposta pela própria Lei 9.656 em que a ANS não regula os prestadores privados senão somente as operadoras, tínhamos a certeza de que muito há a ser feito.

Em meados de 2.010, foi criada a Gerência de Regulação em Saúde Suplementar no município de São Bernardo do Campo, nesse momento a única coisa que sabíamos era que havia uma cobertura acima de $60 \%$, com base nos dados da própria Agência Nacional de Saúde Suplementar. Uma coisa era fato: nesse momento era fundamental articulações com a Saúde Suplementar no município visando à otimização dos prestadores privados e buscando a co-responsabilização das ações e serviços de saúde dentro do município. Era preciso desenvolver mecanismos, ferramentas que potencializassem a responsabilização desses atores da saúde suplementar, olhar para a regulação social para assegurar a máxima efetividade na prestação de serviços em saúde no município no sentido mais amplo da palavra. Garantindo a organização e o planejamento dos serviços, sabíamos da qualidade da prestação de serviços que buscávamos para todos os munícipes, cobertos ou não pela saúde suplementar.

Uma dúvida que me consumiu por algum tempo era se a gerência de regulação em saúde suplementar não deveria estar ligada a vigilância sanitária ou ao 
departamento hospitalar, ou quem sabe a ouvidoria. Uma coisa era evidente, a transversalidade da regulação em saúde suplementar é um aspecto marcante nessa experiência, sabiamente nosso Secretario, Dr. Arthur Chioro, pessoa de raro conhecimento dentro da saúde pública em nosso país, optou em aloca-la dentro do Departamento de Apoio à Gestão, departamento de grande transversalidade.

Existiam algumas diretrizes quando da criação da Gerência de Regulação em Saúde Suplementar, eram elas: melhorar a gestão da informação do setor privado, eleger pelo menos uma linha de cuidado pra trabalhar com a saúde suplementar, optamos pela materno-infantil (que ao longo do caminhar a rede se tornou a rede cegonha). Pensar formas que agilizassem o ressarcimento ao SUS, pois sabíamos o quão moroso era.

Vamos discorrer um pouco como caminhou cada uma dessas diretrizes iniciais e depois mais um pouco dessa experiência no município de São Bernardo do Campo.

1 - Melhoria da gestão de informação - Sabemos que os Sistemas de Informação no SUS contém dados referentes à população e sua saúde e podem ser utilizados pelo setor privado no seu planejamento de ações e serviços em saúde, inclusive quanto à oferta de serviços. O sentido inverso não ocorre, pois não existem dados suficientes no setor privado, o que dificulta inclusive para o gestor o exercício de seu papel como autoridade sanitária no território. Feitas essas considerações, optamos em começar a trabalhar com o Cadastro Nacional de Estabelecimentos de Saúde, não conhecíamos qual era a carga instalada em nossos serviços de saúde privados, os dados que tínhamos estavam muito desatualizados, serviços que não atualizavam o CNES há anos, iniciamos o trabalho de qualificação desse Sistema já de forma transversal, em conjunto com a Vigilância Sanitária, Setor de Informação e com o Controle e Avaliação. Pegamos o que havia de informação oficial no sistema, articulamos com a Vigilância para que, quando da renovação dos alvarás fosse feito uma contagem de leitos e equipamentos; junto a Avaliação e Controle, realizamos visitas individualizadas sempre com apoio de nosso Secretario de Saúde explicando a importância do planejamento em saúde na obtenção desses dados, além disso, a importância para o próprio serviço em conhecer qual a oferta real, quais seus profissionais, etc. Conseguimos importantes avanços nesse sentido, acredito que conseguimos atingir minimamente nosso primeiro objetivo de melhorar a qualidade do Sistema. Após essa primeira etapa iniciamos outra série de visitas visando a 
otimização do Sistema CIHA, e outros como SIM e SINASC, traçamos toda uma estratégia de qualificação desses sistemas que vem se mostrando promissora.

2 - Quanto à linha de cuidado materno infantil: Precisávamos reduzir a taxa de mortalidade materno-infantil, isso era um desafio bastante complexo e precisávamos instituir a regulação em saúde suplementar no município e na região, mais uma experiência de interdisciplinariedade dentro de Secretaria.

Realizamos o $1^{\circ}$ Encontro Regional de Saúde Suplementar, com o tema "Cenário Atual e as Perspectivas para a Saúde Suplementar e os SUS na Região do Grande ABC", realizado no Consórcio Intermunicipal do ABC. O encontro contou com a presença dos municípios vizinhos, integrantes do colegiado de gestão regional, bem como de todos os atores privados envolvidos, hospitais e operadoras de saúde, além de representantes do Ministério de Saúde, Agência Nacional de Saúde Suplementar, Associação Paulista de Medicina, Usuários, Sindicatos e Gestores. Desse encontro resultou a primeira pactuação conjunta entre a esfera pública do sus e a saúde suplementar no sentido de se construir uma parceria do setor público com o setor privado visando o fortalecimento do sus no nível local. Visto que mortalidade infantil era um problema importante para o município e que a saúde suplementar respondia por parcela significativa desses óbitos, o passo seguinte foi a realização de um encontro com a Associação Paulista de Medicina, Operadoras e Prestadores Privados do município, no qual a Secretaria Municipal de Saúde de São Bernardo do Campo apresentou os dados da mortalidade materno-infantil do município.

A aproximação com o segmento privado estava apoiada na cooperação entre os serviços e na responsabilidade sanitária, que independe na natureza jurídica do serviço. O passo seguinte foi agendar visitas com prestadores de forma individualizada e apresentar os dados de cada serviço. "produtos e aprendizado com a vivência" as visitas serviram para criar espaços sempre muito produtivos. Todas as instituições visitadas indicaram participantes para integrar o comitê de mortalidade materno infantil do município, existe um monitoramento constante pelo Comitê sempre envolvendo o setor privado. Efetivamente tem se diminuído progressivamente a taxa de mortalidade infantil, bem como, existe um acompanhamento das ações para redução da mortalidade materno-infantil no setor privado que conseguiu entender que não adianta o Setor Público buscar essa redução sem o apoio do setor privado, não 
esquecendo que a cobertura de saúde suplementar (oficialmente) no município é de $63 \%$ da população.

3 - Formas alternativas de ressarcimento que não ferissem a legislação posta, bem como, pudesse levar em consideração a universalidade dos serviços e a equidade, buscando a integralidade. Na rotina de monitoramento de ações da Gerência de Regulação em Saúde Suplementar constatamos que muitos usuários de terapia renal substitutiva e oxigenoterapia domiciliar estavam em nossos cadastros e também eram beneficiários da saúde suplementar. Após a identificação desses pacientes, foi realizado um contato individual com cada um desses usuários para saber qual era a operadora que havia negado atendimento, condições do contrato, se era anterior a 1.999 ou não, se estava em carência, dentre outras. Perguntávamos se gostariam de ser atendidos por seus planos privados de saúde; a resposta foi unânime, sim, mas infelizmente "não temos direito de utilizar esse serviço/procedimento, porque o meu contrato não prevê cobertura". Após análise, esclarecíamos que tinham sim direito de serem atendidos por seus planos na grande maioria dos casos, e a resposta era geralmente a mesma, diziam que queriam ser atendidos por seus planos de saúde, afinal pagavam com tanto "sacrifício".

Nesse momento a dúvida era para onde encaminhar essas pessoas que querem exercer seus direitos? Três hipóteses surgiram nesse contexto: $1^{\mathrm{a}}$ encaminhar para a Faculdade de Direito São Bernardo (autarquia municipal); $2^{\mathrm{a}}$ encaminhar as demandas para o Procon (a desvantagem era a limitação de renda familiar de até três salários-mínimos); $3^{a}$ - Ministério Público (no sentido de notificar cada negativa de atendimento feita pelas operadoras, de que estão utilizando o SUS, com expressa manifestação de vontade nesse sentido).

Fizemos conversas com todos e optamos pela parceria com a Faculdade de Direito São Bernardo para atendimento jurídico desses munícipes. Pelos seguintes motivos, entendemos que era o melhor para os munícipes pela própria natureza dos serviços de saúde, pois retirou-se a restrição de renda familiar para atendimento jurídico, bem como, horário de atendimento flexível através do posto do Poupatempo das 7 às 19 horas, de segunda à sexta; aos sábados: das 7 às 13hs. Os alunos da Faculdade do escritório escola passaram a ser multiplicadores, difundindo o conhecimento mais amplo da legislação em saúde (inclusive realizamos cursos de capacitação com os alunos). 
A próxima etapa era iniciarmos o convênio da seguinte forma: estávamos com uma lista de espera em oxigênio domiciliar, chamamos cada um dos usuários da lista que tinham cobertura de saúde suplementar e que estavam com as negativas injustificadas dos respectivos planos, eles continuavam em nossa lista de espera só que enquanto isso eram propostas ações judiciais contra os respectivos planos, a medida que as liminares eram concedidas e os usuários atendidos por seus planos. Já temos mais de 25 liminares concedidas para tratamento de oxigênio domiciliar. Outras para TRS.

A intersetoriedade é, realmente, o forte da Gerência de Regulação em Saúde Suplementar. Outra ação vem sendo desenvolvida junto à assistência farmacêutica: estamos orientando usuários que chegam na assistência farmacêutica em busca de medicamentos oncológicos não cobertos pela Relação do Sus e que têm saúde suplementar, como uma forma de diminuir a judicialização contra o SUS, com um trabalho conjunto de orientação jurídica.

Dentro da Central de Regulação do Município algumas ações também foram desenvolvidas.

Com o intuito de regular as solicitações de transferências inter-hospitalares solicitadas pela Saúde Suplementar para o Serviço Público de Saúde, foi elaborado formulário específico, que abrange os dados clínicos e a necessidade do paciente, mas também os dados do paciente, da operadora do plano de saúde, data da contratação do plano, cobertura e abrangência do plano, se há carência e sua especificação.

A implantação deste fluxo de transferência inter-hospitalar possibilitou não o cerceamento do acesso destes usuários, mas sim garantir a efetividade da regulação e o devido acesso ao serviço público. A regulação se dá tanto no âmbito médico, com critérios de priorização e classificação de risco baseados em protocolos, quanto no âmbito administrativo com a verificação dos dados informados pela operadora do plano de saúde e, em conjunto com a gerência de saúde suplementar que verifica a legalidade e obrigatoriedade do atendimento no setor privado.

Os critérios regulatórios implementados vem se mostrando eficientes e com boa aceitação das Unidades Solicitantes em preencher adequadamente o formulário e com a resolução e posicionamento da Central de Regulação quanto à solicitação. Havendo efetivamente uma aproximação entre os serviços público e privado no nosso 
município e um maior conhecimento do caso solicitado tanto na esfera médica quanto na administrativa.

Figura 1: Solicitações de transferências inter-hospitalares requeridas pela Saúde Suplementar, segundo o mês.

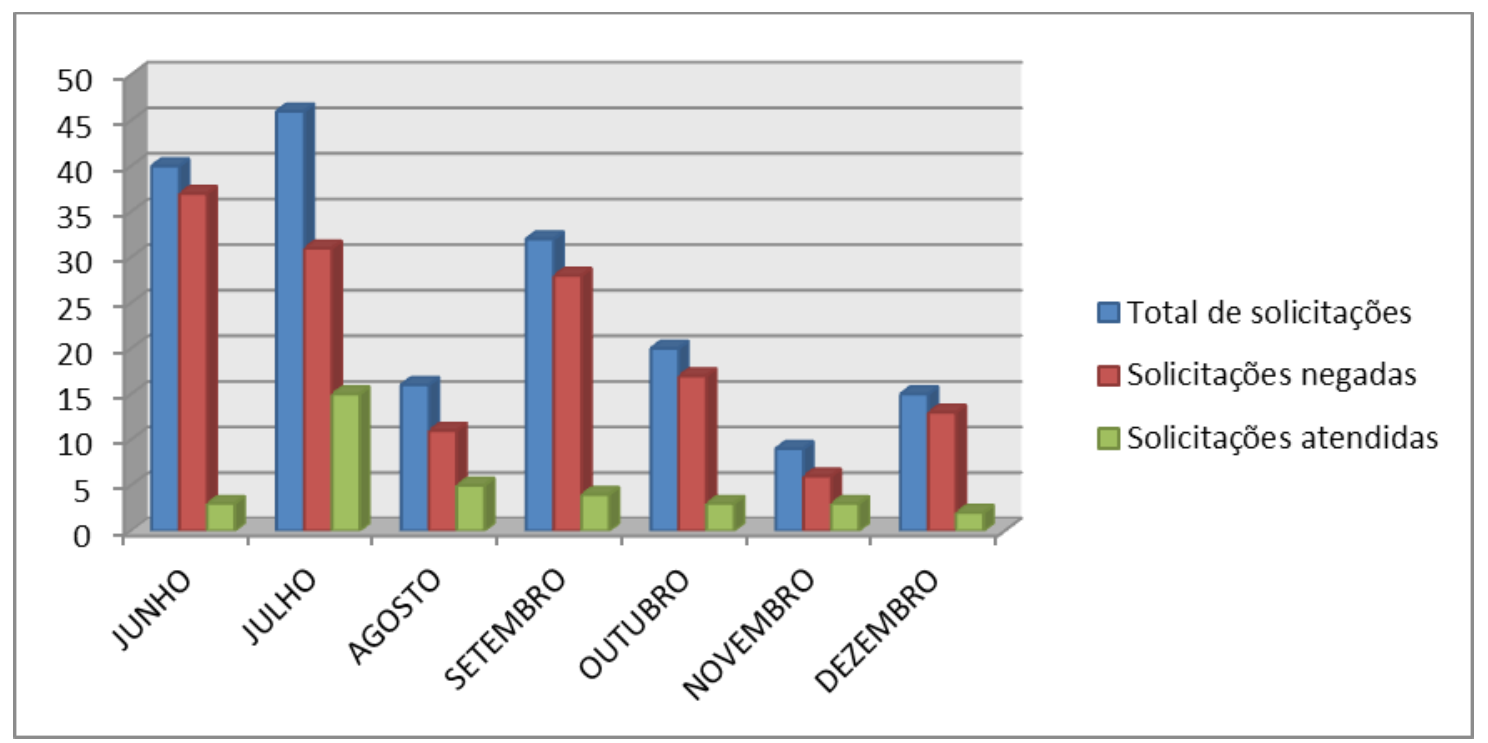

Observa-se que as solicitações de transferência inter-hospitalar vêm diminuindo nos meses subsequentes à implementação do fluxo. Acreditamos que os principais motivos para tal acontecimento foi à exigência de justificar a impossibilidade legal da permanência do paciente no serviço privado de saúde e a necessidade de transferência para o serviço público.

A principal problemática enfrentada refere-se à carência. Muitas vezes há desrespeito às normas legais estabelecidas. Cito alguns casos práticos:

Ocorreram dois casos de pacientes que se encontravam em hospital privado com diagnóstico de abortamento. Em ambos os casos, a operadora do plano de saúde negou a cobertura ao procedimento alegando carência de 300 dias para parto. Ocorre que complicações no processo gestacional caracterizam urgência, sendo a carência de 24 horas após a data da inscrição. Logo, as usuárias têm direito ao atendimento pelo plano de saúde, não procedendo à alegação feita pela operadora.

Outro caso foi de uma usuária internada com diagnóstico de IAM. O convênio cita carência de 24 meses por doença pré-existente referente ao aparelho circulatório. No entanto, segundo entendimento da regulação médica, não há, necessariamente, ligação intrínseca entre a doença pré-existente e a patologia atual. 
Paciente diagnosticado com AVC estando na emergência de uma unidade hospitalar privada. A carência declarada foi de doença pré-existente. Contudo, segundo informação do próprio médico solicitante o paciente estava em estado grave, correndo risco iminente de perder a vida, o que caracteriza urgência e emergência cuja carência é de 24 horas.

Todos os casos supracitados foram regulados e, apesar da discordância, a Central de Regulação encaminhou os pacientes para o Serviço Público visando o adequado tratamento do usuário.

Outra atuação com a Saúde Suplementar consiste na transferência de pacientes que dão entrada na rede pública municipal e possuem plano de saúde. Nesses casos, a Central de Regulação entra em contato com a operadora do plano e solicita a transferência para a rede conveniada.

O trâmite administrativo não é uniforme, cada operadora tem um fluxo próprio para a remoção de pacientes. Algumas, inclusive, não possuem centrais específicas para remoção de pacientes. Nesses casos, a busca do leito hospitalar e do serviço para a remoção é feita pela Central de Vagas Municipal.

Toda a experiência vivida desde a criação de Gerência de Regulação em Saúde Suplementar vem mostrando que o único vencedor é a população, quando o SUS se aproxima do setor privado para realizar ações e serviços de saúde.

Ela demonstra que, muito embora existam diferenças gigantescas entre 0 sistema público e o privado pelas suas próprias naturezas, sabemos que os interesses são diferentes, mas também existem problemas comuns que, com bom senso e esforço dos gestores, é possível mudar o que está instituído.

Ninguém quer reinventar a roda, apenas fomentar a importância de conseguirmos romper barreiras de que o setor público e o setor privado têm interesses $100 \%$ diferentes e que nunca conseguem caminhar juntos. Com isso conseguimos, sim, fortalecer o Sistema Único de Saúde, na nossa experiência no âmbito municipal, mas com estratégias potentes para fazer muito mais. 